\title{
enfoque
}

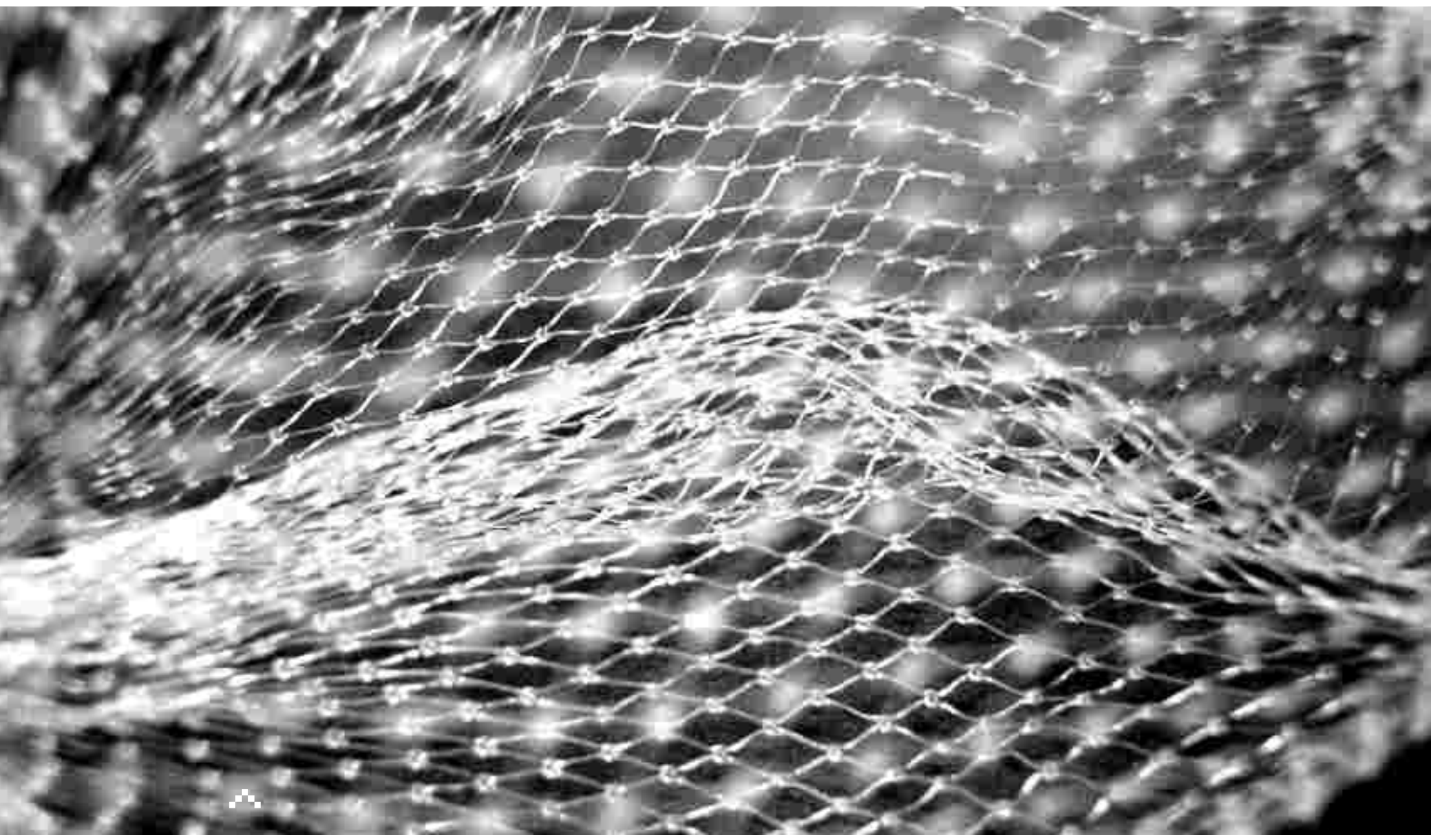

\section{BLOGGING desde el sur}

"N

El principio de conectividad generalizada refiere a que hoy "todo comunica y todo está en red: personas,

máquinas, objetos, monumentos, ciudades". A. Lemos. Foto J ane M. Sawyer
Los blogs impactaron en internet al facilitar la publicación de contenidos y crear un mundo dentro de la web conocido como la blogósfera. Un mundo cuyo crecimiento es permanente y continuo: cada día se crean cien mil nuevos blogs. Sin embargo, esta actividad de generar y publicar contenido en internet aún no tiene presencia suficiente dentro de la población de habla hispana que representa, según Technorati, solo el 3 por ciento de la blogósfera'. 
Los blogs simplificaron tanto la tarea de creación de sitios webs, que millones de personas que no tenían presencia activa como generadores de contenido en internet, hoy publican en la web con regularidad.

J osé Luis Orihuela, profesor en la Facultad de Comunicación de la Universidad de Navarra, autor del blog «eCuaderno.com»y del libro La revolución de los blogs, caracteriza a los blogs como "herramientas que facilitan a la gente corriente hacer comunicación pública sin complicaciones técnicas y sin editores profesionales, que se inscriben en el amplio campo del software social".

Ante la pregunta de por qué los profesionales de la comunicación debemos tener en cuenta el fenómeno blog, Orihuela señaló que "son un medio de comunicación de escala normal mente comunitaria, aunque la blogósfera en su conjunto representa lo que puede considerarse como un quinto poder debido a su capacidad para controlar las esferas mediáticas y políticas tradicionales, así como para establecer sus propias agendas."

Si bien "en términos cuantitativos los blogs estrictamente autobiográficos son mayoritarios [...] en términos de impacto, los blogs que cuentan son los temáticos, ya que son los que tienen interés público. La especialización temática de la blogósfera y el desarrollo de herramientas de ranking sectorial de blogs y seguimiento (tracking) de conversaciones permiten, cada vez con mayor precisión, tomar el pulso de la blogósfera sobre cualquier tema, marca o producto que interese investigar", afirma el profesor Orihuela.

La unidad de publicación que utilizan los blogs se Ilama post y actualmente se publican 1,3 millones de post por día, ${ }^{2}$ casi el doble que el año pasado, según informa David Sifry, creador y fundador de Technorati, ${ }^{3}$ una exitosa guía de blogs en internet. Sifry comparte la información de los cambios que se generan en la blogósfera a través de entregas regulares, trimestrales, que postea ${ }^{4}$ en su blog Sifry's A lert. La información más reciente corresponde a los datos de octubre de 2006, que indican que hay más de 57 millones de blogs y que el crecimiento de la blogósfera continua en ascenso permanente aunque un poco más lento que el trimestre anterior. ${ }^{5}$ A demás, señala que de este total, el 55 por ciento ha sido actualizado al menos una vez en losúltimos tres meses.

"Si cruzamos las cifras publicadas en noviembre por Technorati (57 millones de weblogs) con las de Netcraft (cien millones de sitios web), la proporción de blogs es asombrosa, aunque habría que considerar con más detalle la base metodológica de cada estudio", advierte Orihuela.

Según la empresa Netcraft, ${ }^{6}$ los blogs han impulsado, junto a los pequeños negocios, el crecimiento de sitios web en los últimos dos años y medio. El nuevo reporte de la encuesta que realiza Netcraft ${ }^{7}$ desde 1995 para medir la cantidad de dominios web, señala que en octubre de 2006 se registraron cien millones de sitios web. Además, indica que en los últimos dos años el ritmo del crecimiento se aceleró: en tanto 2005 registró 17 millones más que el año anterior, en 2006 contabilizaron 27,4 millones de sitios nuevos. En concreto, la cantidad de sitios web, que es una forma de hablar del contenido en internet, se duplicó de marzo de 2004 a octubre de 2006 y este crecimiento fue motivado principalmente por el fenómeno blogs y los pequeños negocios, asegura Netcraft.

Sin embargo, y pesar del éxito de los blogs en internet, el contenido en castellano publicado es escaso. De hecho, el castellano representa solo el tres por ciento de la blogósfera que reúne Technorati. El inglés está a la cabeza con un 39 por ciento, y lo siguen el japonés y el chino con 33 y diez respectivamente. ${ }^{8}$

Orihuela explica que "la blogósfera anglosajona está bien asentada y el medio está culturalmente asumido. En China la situación es bastante peculiar por razones del dominio público, y la parte más activa e interesante de esa blogósfera está constituida por periodistas, muchos de los cuales ponen en riesgo su libertad para hacer blogging". En cuanto al fenómeno blog en Latinoamérica, señala que "la blogósfera hispana arranca en A mérica Latina (M éxico y Argentina), y está presente aunque de manera desigual en toda la región".

De acuerdo con el profesor de la Universidad de Navarra, "una de las grandes contribuciones de los l:.

David Sifry, "State of the Blogosphere, October 2006". «ww.sifry.com/alerts/archives/0 00443.html> Publicado el 6 de noviembre de 2006. (11/11/06). $2::$

Ibídem.

3:.:

Technorati indexa los blogs cuando el creador lo agrega a la guía.

4:.

Postear: publicar un post. 5:.:

El informe señala que se crean cien mil nuevos blogs por día (octubre 2006).

6:.:

Empresa de servicios de Internet con base en Bath, Inglaterra. swww.netcraft.coms $7:$ :'

Netcraft Web Server Survey. Noviembre 2006

«ttp://news.netcraft.com/archive s/2006/11/01/november_2006_w eb server survey.htmls $(1 \overline{1} / 11 / 06)$ 8:.'

David Sifry, 0. cit.
Por Soledad Caballero Fotos Morguefile.com 


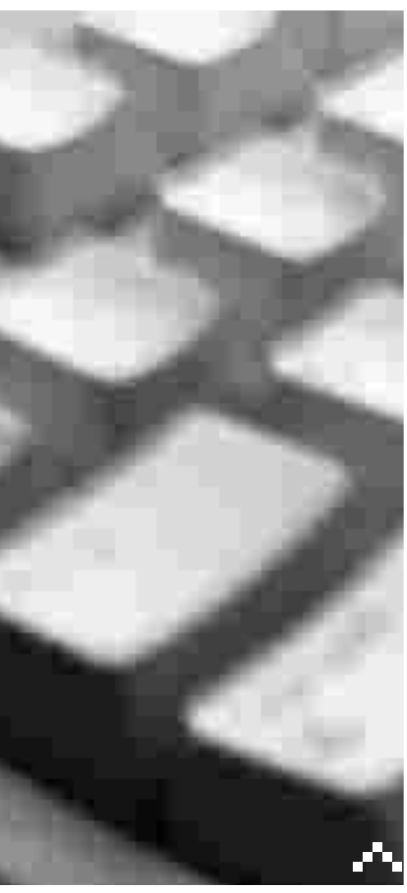

"ru"

El principio de la liberación del polo de la emisión muestra "la emergencia de voces y discursos antes reprimidos". A. Lemos.

Foto Hekuran Iberdemaj

Encuesta Nacional de Hogares Ampliada del Instituto Nacional de Estadística de Uruguay correspondiente al segundo trimestre de 2006 http://www.ine.gub.uy/enha200 $6 /$ enha.asp > (11/11/06)

10::

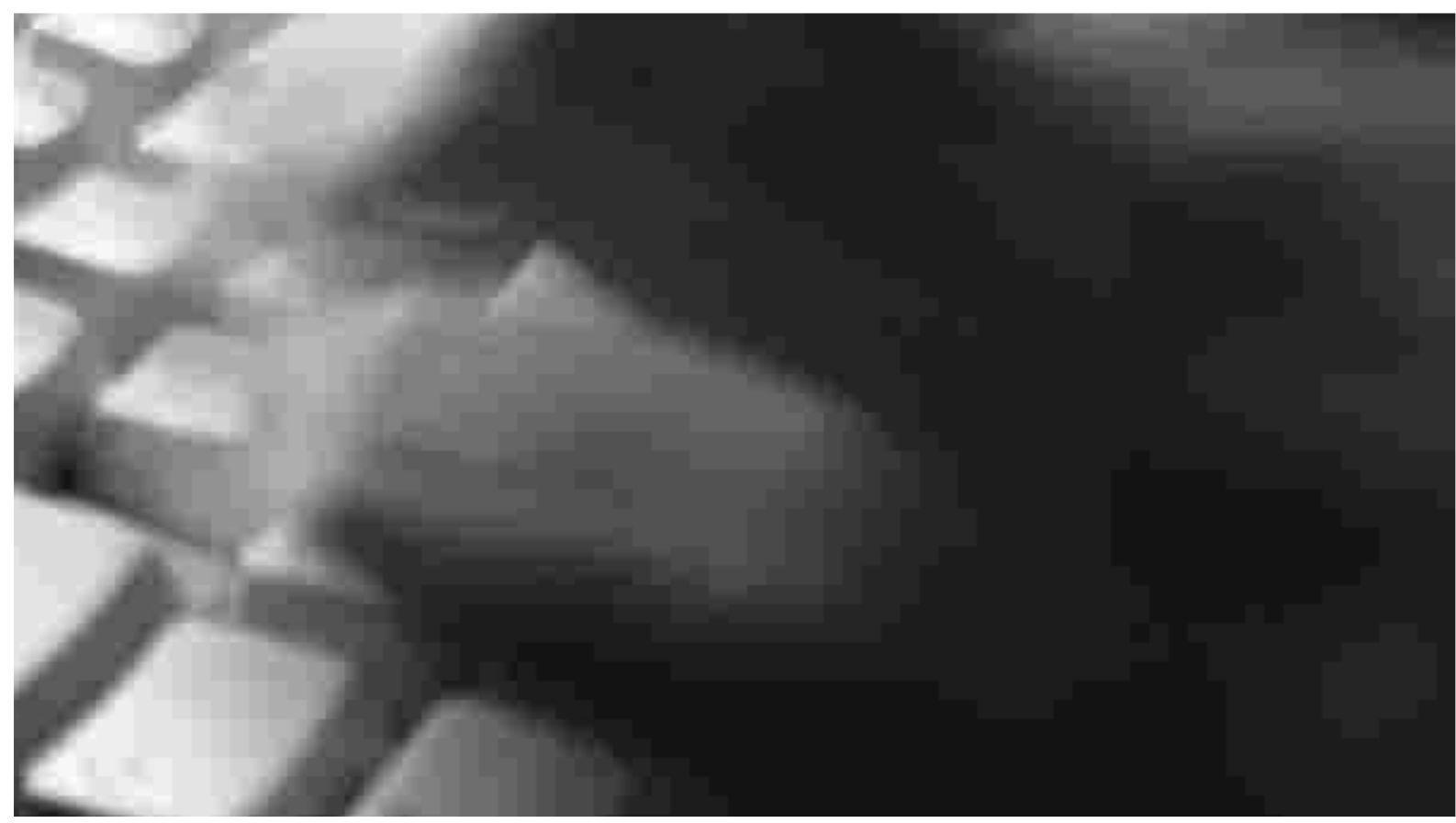

blogs en la región latinoamericana ha sido el haber facilitado la circulación y el acceso a fuentes internacionales de información, a estudios académicos, informes y ensayos que han facilitado la labor de periodistas, estudiantes, investigadores y educadores".

Al observar el fenómeno blogs en Uruguay, nos encontramos con que no hay aún estudios y cifras confiables para saber el lugar que éstos ocupan en los usos que hace de internet el casi 29,4 por ciento de la población que es usuaria de la web. ${ }^{9}$ Pero se puede tener en cuenta que este porcentaje incluye como usuarios de internet en Uruguay a aquellos que se conectaron al menos una vez en los últimos seis meses, y la frecuencia de uso de internet es una variable importante para definir un probable perfil de blogger. De esta forma, el universo posible de bloggers en Uruguay se acota un poco más ya que del total de usuarios de internet, el 48 por ciento se conecta al menos una vez a la semana, y un 37 por ciento al menos una vez al día. ${ }^{10}$ Es de esperar que en este último grupo se encuentren los potenciales bloggers en Uruguay.

Algunos de los bloggers uruguayos pueden encontrarse reunidos en sitios como Weblogs
〈wWw.weblogs.com.uy〉 y Blogsuy 〈blogsuy.net〉, Blogsuy, por ejemplo, es un agregador que reúne blogs escritos por uruguayos y publica en la página principal las entradas que éstos postean. Es como si fuera Google News, pero con blogs de Uruguay que han sido indexados en forma manual. Para aparecer en Blogsuy hay que anotarse y ser aceptado por el creador del sitio, Pablo Viojo, un uruguayo que se en Chile hace más de un año. Lanzó Blogsuy en junio de 2005 y se encargó de anotar él mismo los primeros treinta blogs, pero luego otros comenzaron a sumarse y ahora ya son más de 160 . El criterio de selección que utiliza para aceptar blogs en Bloguy es que sean creados por uruguayos o escritos desde Uruguay. No es una iniciativa de corte comercial, al menos hasta el

En cuanto a los temas que inquietan a los investigadores de la blogósfera actualmente, Orihuela nombró a "la construcción de la propia identidad y reputación en la red, las nuevas formas de autoridad, la relación entre blogs y el sistema mediático tradicional, el potencial de los blogs en la difusión del conocimiento científico y su valor como herramientas de publicación y revisión entre pares, la circulación de dedica al desarrollo de software, tiene 25 años y vive momento, señala Viojo. 


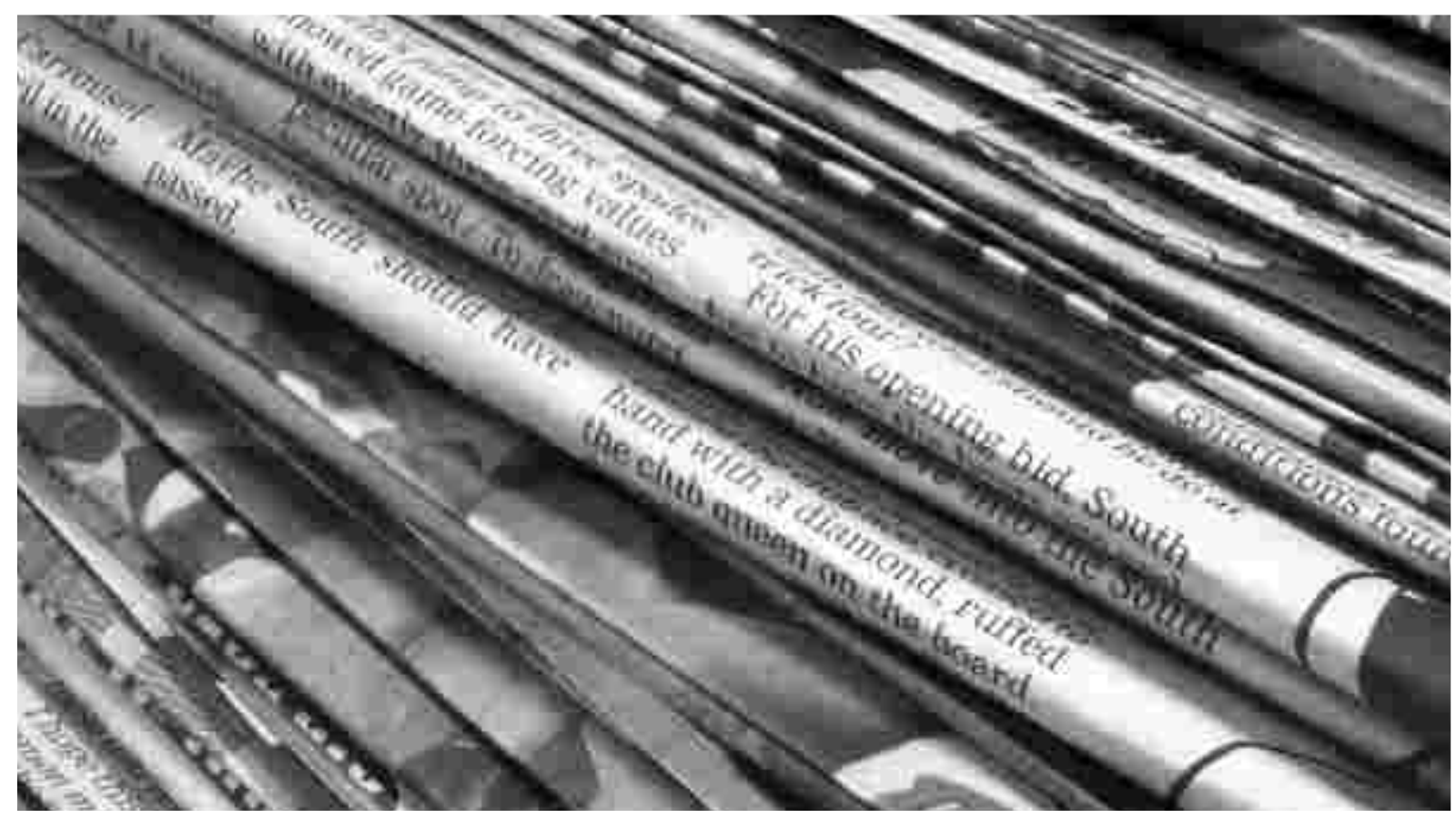

memes, la representación y el funcionamiento de redes basadas en enlaces recíprocos, la relación entre blogs y buscadores, y en general los fenómenos políticos y económicos que podrían encuadrarse bajo el paradigma 'long tail'". Estos temas generan controversia y debates en torno a los cuales se van consolidando distintas posturas teóricas, técnicas y políticas.

\section{Blogs: un fenómeno de la cibercultura}

André Lemos, ${ }^{11}$ doctor en Sociología, Paris V, Sorbonne, profesor de la Facultad de Comunicación dela Universidad Federal de Bahía e investigador de la cibercultura a la cual define como "la cultura contemporánea marcada por las tecnologías digitales" ${ }^{12}$ explica que los blogs son formas de publicación de las que cual quier persona puede disponer fácilmente para comenzar a emitir informaciones, emisiones de audio (audioblogs) o videos (vlogs) y fotos (fotolog), ya sean de carácter personal, periodístico, humorístico, literario.

Para Lemos, la nueva dinámica técnico social de la cibercultura instaura tres principios: el de la liberación del polo de la emisión, el de conectividad generalizada y el de re-configuración. "El caso de los blogs (audioblogs, fotologs, vlogs) demuestra ser un fenómeno que tiene origen en la liberación de la emisión y en la re-configuración de la industria mediática y de sus prácticas de producción de información", afirma el investigador.

La liberación del polo de la emisión alude a "las diversas manifestaciones socioculturales contemporáneas", que "muestran que lo que está en juego con el exceso y la circulación viral de información es nada más ni nada menos, que la emergencia de voces y discursos antes reprimidos por la edición de información en los medios de comunicación masivos".

El segundo principio, de conectividad generalizada, señala Lemos, refiere a que está "todo en red" y que "la red está en todo lugar" así como que "el verdadero computador es la red". Esta conectividad en red comenzó con la transformación de la computadora personal (PC) en el computador colectivo con el surgimiento de internet y su popularización en los años noventa y posterior transformación en el actual computador colectivo móvil en la era de la ubicuidad y la computación inserta por doquier (pervasive computing) de este inicio del siglo XXI, con la explosión de los teléfonos celulares y de las redes WiFi. Hoy, "todo comunica y todo está en red: personas,

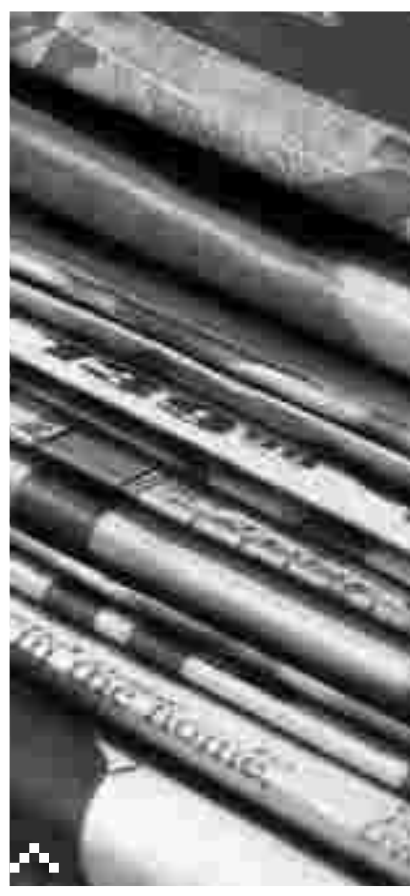

+19

El principio de reconfiguración alude a la modificación de "las prácticas, las modalidades mediáticas, los espacios, sin la sustitución de sus respectivos antecedentes" y "de las estructuras sociales y de las instituciones".

A. Lemos.

Foto Jane M. Sawyer (USA)

\section{$11::$}

Blog de André Lemos, Carnet de Notes:

http://www.facom.ufba.br/ciber pesquisa/andrelemos/> 12:.:

Lemos, André; Cunha, Paulo (orgs). Olhares sobre a Cibercultura. Sulina, Porto Alegre, 2003; pp. 11-23 "Cibercultura: Alguns pontos para compreender a nossa época".

André Lemos

(http://www.facom.ufba.br/ciber pesquisa/andrelemos/cibercultur a.pdf>) $(13 / 11 / 06)$ 
Enlaces para introducirse en la blogosfera hispana

Extraído del0 Steps into the Spanish Speaking Blogosphere, por José Luis Orihuela, www.ecuaderno.com/blogosphere y el Weblog sobre Weblogs de Mariano Amartino weblogs.clarin.com/weblogs

\section{Herramientas de publicación \\ Blogger blogger.com \\ Livejournal livejournal.com \\ Movable Type movabletype.org \\ Typepad typepad.com \\ Wordpress wordpress.org \\ La Coctelera lacoctelera.com}

\section{Agregadores de blogs}

Argentina argenblogs.com.ar weblogs.com.ar

Bolivia blogsbolivia.blogspot.com

Brasil blogs.com.br

Chile blogs.cl

Colombia blogscolombia.com

Costa Rica ticoblogs.com

Cuba cubaperiodistas.cu/blogueros/directorio_provincias.html

Ecuador ecuablogs.com

España bitacoras.com

Guatemala blogschapines.com

México blogsmexico.com

Nicaragua blogsnicaragua.com

Panamá blogspanama.com

máquinas, objetos, monumentos, ciudades", señala Lemos.

El tercer principio que impone la nueva dinámica técnico-social, según Lemos, es el de re-configuración. El investigador brasileño señala que "debemos evitar la lógica de la sustitución o aniquilamiento ya que, en varias expresiones de la cibercultura, se trata de re-configurar las prácticas, las modalidades mediáticas, los espacios, sin la sustitución de sus respectivos antecedentes".

En este sentido resulta interesante observar la interacción e integración entre los medios de comu-nicación tradicionales y los blogs. Los medios tradi-cionales han incorporado a sus propuestas, conte-nidos producidos por bloggers a través de alianzas como la de Technorati con Associated Press $e^{13}$ incluso agregan en sus sitios web enlaces a lo que se comenta en la blogósfera sobre un determinado tema informa-do por el medio, como es el caso de The Washington Post. De acuerdo con el informe de David Sifry, la blogósfera reacciona frente a sucesos importantes en el mundo, ya que se muestran picos de publicación de post cuando éstos ocurren. Por ejemplo, dice Sifry, uno de estos picos se constató en julio de 2006 en vinculación al conflicto Israel-Hezbollah, así como
Paraguay paraguay.blogalaxia.com

Perú blogsperu.com

Puerto Rico puertoblogs.com

República Dominicana blogsdominicanos.com

Uruguay Blogsuy blogsuy.net Weblogs weblogs.com.uy

\section{Búsquedas de Blogs y Posts}

Agregax agregax.es

Búsqueda de Blogs en Google google.es/blogsearch

\section{Promoción de blogs}

Enchílame www.enchilame.com

Fresqui fresqui.com

Menéame meneame.net

Neodiario neodiario.net

\section{Metablogs}

Blogs que hablan de los blogs y ofrecen recursos para bloggers eCuaderno ecuaderno.com

Herramientas para blogs mmadrigal.spaces.live.com

Linotipo rvr.typepad.com/linotipo

Reflexiones e irreflexiones fernand0.blogalia.com

Unión de Bloggers Hispanos uniondebloggershispanos.com

Utilidades y recursos para blogs utilidades.bitacoras.com

Weblog sobre weblogs weblogs.clarin.com/weblogs

Zapin.info zapin.info

Blogs académicos www.academicblogs.org

con otras escaladas en las tensiones de Medio Oriente. ${ }^{14}$

Lemos señala que la re-configuración, tal como él la entiende, encuentra eco en el concepto de remediation ${ }^{15}$ de J ay David Bolter y Richard Grusin, pero aclara que comprende además la idea de modificación de las estructuras sociales, de las instituciones y de las prácticas de comunicación.

Por otro lado, los blogs a veces conforman comunidades donde los usuarios/lectores pueden agregar informaciones y comentarios, y en éstas se ve "claramente la liberación del polo de la emisión (cualquiera puede hacer su blog) el principio de red (los blogs que hacen referencia a otros blogs) y la reconfiguración con nuevos formatos de diarios, de publicaciones periodísticas, de emisiones sonoras y de video, de literatura, etc." , explica Lemos.

Sin embargo, a toda la potencialidad de actividad de comunicación, conexión y reconfiguración que introduce la tecnología, y en este caso particular los blogs, actualmente debemos enmarcarla en algunos aspectos que se pueden presentar como limitantes: el acceso a internet, el conocimiento de idiomas y la voluntad concreta degenerar contenidos. :: 


\section{Con Raúl Echeberría, director ejecutivo de LACNIC}

\section{Debates vinculados a INTERNET}

La limitada presencia del castellano en la blogósfera se inscribe en el marco de una insuficiente representación de la lengua en la totalidad de internet, si bien es el segundo idioma nativo más hablado del mundo, después del chino, y en el mundo hay unos 450 millones de personas que hablan español.

Actualmente, los contenidos en internet están escritos predominantemente en inglés, y en segundo lugar en francés. Y la disponibilidad de contenidos en casteIlano es muy importante para el desarrollo de conocimiento, desarrollo tecnológico y desarrollo científico de los países de habla hispana, señaló Raúl Echeberría, director ejecutivo de LACNIC. La "insuficiente" presencia del castellano en internet se relaciona con el hecho de que la población de habla hispana está concentrada en América Latina - más de 300 millones de hispanoparlantes- una región con "muy baja penetración de internet, menor al quince por ciento", puntualiza el director ejecutivo de LACNIC. Y a su vez la falta de contenidos en castellano impacta en el problema del acceso a internet en América Latina, ya sea por la exclusión que implica de hecho para aquellos que no hablan inglés, como por los costos de las tarifas de acceso a internet que hoy están asumiendo países como Uruguay.
Por un lado, una mayor cantidad de contenido en castellano es importante "para que más gente pueda hacer cosas útiles con internet, porque si no, muchas personas que no hablan otros idiomas ven limitado el impacto que el uso de la herramienta tiene sobre su vida", explicó el directivo de LACNIC. Por otro lado, la falta de contenido en castellano también incide en las tarifas de acceso a internet, porque el acceso a más contenido local cambiaría la ecuación de consumo y conectividad, señala Echeberría. Esto se debe a que, para los países como Uruguay, que están alejados de los principales lugares donde está la concentración más grande de redes, usuarios y conocimiento disponible (los backbones), conectarse a internet sale muy caro. "Por lo que paga por un enlace un proveedor de internet de A mérica del Sur, si se compra una conexión entre Londres y Nueva York se recibe, por el mismo dinero, sesenta veces más capacidad de transferencia de datos", afirmó Echeberría. La explicación para esta situación está en el hecho de que "la mayoría de los países de América Latina, como Uruguay, se conecta a redes norteamericanas y a diferencia de los mecanismos de tarifación de la telefonía básica donde cada parte paga la mitad de la conexión somos nosotros que pagamos el cien por ciento de la conexión para conectarnos a esas redes

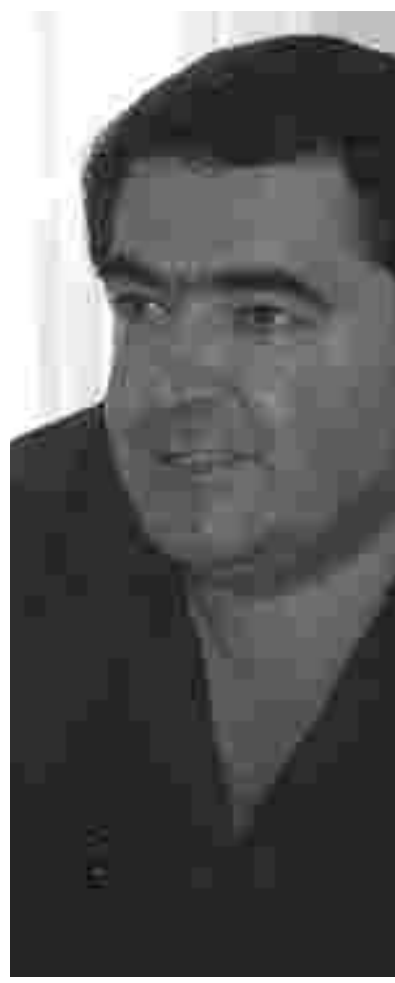

l::

LACNIC. Registro de Direcciones de internet para América Latina y el Caribe.

$2:$.

El quince por ciento de penetración de internet en América Latina es muy bajo, sobre todo teniendo en cuenta que el acceso está focalizado en las principales ciudades y hay muchas áreas extensas en la región en que la penetración es incluso menor a esa cifra.

Por Soledad Caballero Foto gentileza de R.E. 
por más que una vez establecida la conexión la comunicación fluye en ambas direcciones". En otras palabras, este costo de interconexión se traduce en una dificultad para fomentar el acceso a internet que si bien ya tiene alrededor de mil millones de usuarios en el mundo, hay aún cinco mil millones que están excluidos, advierteel directivo de LACNIC.

Echeberría ubica a la problemática de interconexión como un problema de gobernanza, y señala que actualmente no hay mecanismos para darle solución. Este tema concreto estuvo presente en el Foro de la Gobernanza de Internet realizado en A tenas (Grecia) del 30 de octubre al 2 de noviembre pasado, y si "aún no nos hemos puesto de acuerdo en cuál es el diagnóstico del problema, mucho menos lo hemos hecho en las soluciones", comenta el director de LACNIC. Sin embargo, apunta que la resolución a esta situación incluye estimular el desarrollo de contenidos locales para que haya mayor necesidad de acceso local, de aspectos de regulación, de promover más canales de conexión regional y de puntos de intercambio de tráfico tanto a nivel nacional, como regional. Y también, de establecer acuerdos entre países para evitar comportamiento de cartels entre proveedores de internet.

El foro de la Gobernanza de Internet reunió en A tenas a representantes de 90 países con 1.400 delegados, tanto de la sociedad civil como del sector privado y del gobierno, quienes por primera vez discutieron en condiciones más equitativas los asuntos vinculados a la gobernanza de internet. Estos temas solían tratarse en reuniones gubernamentales donde los otros actores tenían un rol de observadores, 0 en reuniones de organizaciones no gubernamentales quienes tienen su propios procesos de desarrollo de políticas. Sin embargo, en A tenas, gobierno, sector privado y sociedad civil participaron eincidieron en forma más equitativa incluso en la confección de la agenda de temas a discutir. El foro se concentró en temas vinculados a la multiplicidad de lenguas, los problemas de acceso, los costos de interconexión, la seguridad, el cibercrimen, el derecho a la privacidad y la libertad de ex presión.

Raúl Echeberría participó del foro de Atenas y destacó el protagonismo que tuvieron cuatro temas inter- relacionados: la seguridad, el cibercrimen, la libertad de expresión y el derecho a la privacidad. Esta agenda, comentó Echeberría, denota por un lado las inquietudes que vienen desde sociedades en las cuales su derecho a la libertad de expresión - como China, por ejemplo- o derecho a la privacidad, no están siendo respetados en relación a internet. Por otro lado, reflejan las inquietudes generales por mejorar los sistemas de seguridad y la lucha contra el crimen en internet. En su opinión, "los problemas de seguridad y cibercrimen no se pueden discutir sin tener en cuenta el derecho a la libertad de expresión y el derecho a la privacidad. No podemos comprometer estos derechos en la búsqueda de soluciones a otros problemas", enfatizó. En este sentido, Echebarría advirtió que el tema privacidad es un tema fundamental que en Uruguay ha tenido muy poco debate, al igual que en otras sociedades de la región.

En tanto el asunto de la seguridad, vinculado a la inestabilidad de los sistemas y la inseguridad de la información, "es más tangible", el tema de cibercrimen es un desafío importante. Si bien ya hay muchas leyes que contemplan los posibles delitos en internet, se presentan dificultades en su aplicación. Por ejemplo, la pornografía infantil es delito en todo el mundo, pero la pornografía ("contenido para adultos") no es delito en los países occidentales, y sí lo es en países musulmanes. El desafío es entonces trabajar en el contexto de un medio global como internet con la heterogeneidad vinculada a la tipificación de delitos. Además, el cibercrimen incluye la problemática que tiene que ver con la persecución del delito, el lugar donde se cometió y se juzga el crimen, así como los acuerdos entre países. La Unión Europea ya tiene una convención sobre cibercrimen a la que pueden adherir otros países que no pertenezcan a ella, informó Echeberría.

"Los temas de seguridad y los temas de crimen hay que analizarlos y buscar la mejor forma de atacar el asunto pero con ciertos valores al lado, entre los que están el derecho a la privacidad y la libertad de expresión que son derechos universales que no hay que revisarlos. Hay que hacer un ejercicio responsable de esos derechos, y un ejercicio responsable de los derechos es no violentar los derechos de otro", afirmó Echeberría.:I 